\begin{tabular}{l|l} 
Rev Asoc Colomb Dermatol & $\begin{array}{l}\text { Carta } \\
\text { al editor }\end{array}$
\end{tabular}

\title{
Aprendiendo dermatología en las pieles oscuras
}

\section{Claudia Juliana Díaz Gómez}

Docente de Dermatología y Cirugía Dermatológica. Universidad del Valle

La enseñanza y el entrenamiento de la dermatología de los estudiantes de pregrado y posgrado se realiza mediante capacitación presencial, donde ellos interactúan directamente con los pacientes y observan imágenes fotográficas relacionadas con enfermedades de la piel. Por otro lado, los textos clásicos que contienen ayudas visuales fotográficas que se utilizan durante el aprendizaje, y que son referentes en la Dermatología, muestran con más frecuencia condiciones patológicas o normales de las pieles claras, sin hacer demasiado énfasis en las presentaciones clínicas de las pieles oscuras.

Uno de los grandes retos en la enseñanza y en el aprender dermatológico en las pieles oscuras es realizar el diagnóstico y el tratamiento correcto de la enfermedad, ya que las lesiones varían y se vuelven “no clásicas” debido a la diferencia en el color, en su presentación clínica semiológica, distribución topográfica y en la morfología, en comparación con las pieles más claras. Un ejemplo clásico es el eritema, que en aquellas personas con la piel muy blanca se torna rosado, a diferencia de aquellas con la piel muy oscura, en quienes se puede visualizar como hiperpigmentación parda, azulada o negruzca; también algunas dermatosis propias y otras patologías como la alopecia por tracción y la alopecia fibrosante, el acné nodular, los trastornos en la cicatrización tipo queloide, la hidradenitis supurativa y las alteraciones de la pigmentación suelen ser más comunes o incluso más graves, lo que dificulta el diagnóstico en muchos casos.

Las diferencias clínicas étnicas del color oscuro de la piel se deben al número y al tipo de melanosomas producidos de mayor tamaño, con abundante contenido melánico, de su distribución dentro de los queratinocitos, que tienden a ser menos agrupados, disponiéndose a menudo de manera dispersa y aislada; es decir, la piel oscura fabrica más melanina y lo hace más rápidamente, de tal manera que los trastornos de hiperpigmentación observados son a menudo más intensos y llamativos; esto ocasiona dificultad diagnóstica en algunos casos, como se mencionó anteriormente, ya que en algunas dermatosis se intensifica la presentación clínica. Así mismo, estas diferencias hacen que las terapias instauradas en ciertas patologías, como el melasma, las pigmentaciones posinflamatorias y en otros trastornos de la pigmentación, sean en ocasiones infructuosas y, como consecuencia de ello, haya poca adherencia del paciente al tratamiento. A esta poca adherencia se suman las creencias propias y las costumbres étnicas de la pobla-

\author{
Correspondencia: \\ Claudia Juliana Díaz Gómez \\ Email: \\ claudia.diaz@correounivalle. \\ edu.co

\section{Recibido: 16/12/19} \\ Aceptado: 22/01/20

\section{Conflictos de interés:} \\ No se reportan conflictos de \\ interés.
}

\section{Financiación:}

Ninguna. 
ción, que dificultan a la vez la terapia, con resultados desfavorables.

Teniendo en cuenta que el área geográfica y la población que se atiende influyen en el aprendizaje y en el entrenamiento de los médicos en ciertas patologías, la sección de Dermatología de la Universidad del Valle, del Departamento de Medicina interna en el Hospital Universitario del Valle, en Cali, Colombia, en su programa académico tiene la fortuna de ser un sitio estratégico y un excelente lugar para la enseñanza y el aprendizaje de las enfermedades de la piel en fototipos oscuros afrodescendientes, gracias a su ubicación geográfica y a la convergencia de diferentes poblaciones que provienen en gran parte del Pacífico y del suroccidente colombiano. Diversas enfermedades tropicales poco frecuentes, típicas y atípicas, de tipo infeccioso, como HTLV-1, tumorales y entidades ligadas a costumbres étnicas son atendidas en este centro de referencia.

Las características particulares dermatológicas en esa población hacen que cobre importancia el entrenamiento médico en estos fototipos, para no caer en errores diagnósticos ni emplear exploraciones o tratamientos innecesarios. Así pues, las dermatosis en la piel oscura con su variedad clínica suponen un verdadero reto diagnóstico y de tratamiento, no solo para los dermatólogos sino para otras especialidades. 